\title{
Los contratos sindicales en la ESE HUEM, una modalidad de tercerización laboral
}

\author{
Union contracts in the ESE HUEM, a form of labor outsourcing*
}

\section{Os contratos sindicais no ESE HUEM, uma modalidade da terceirização laboral*}

\author{
Dennys Yazmin Manzano López ** \\ Luis Miguel López Celemin *** \\ Mario de Jesús Zambrano Miranda **** \\ Universidad Libre de Colombia - Cúcuta \\ Universidad de Pamplona
}

\begin{abstract}
Fecha de Recibido: January 17 del 2015
Fecha de Aceptación: March 03 de 2015

Fecha de Publicación: December 21 de 2015

DOI: http://dx.doi.org/10.22335/rlct.v10i2.557
\end{abstract}

* Articulo producto del proyecto de investigación: Diagnóstico del Mercado de Trabajo y Contexto Socioeconómico de Cúcuta y Área Metropolitana, Universidad Libre Cúcuta.

** Economista, Especialista en Gerencia Financiera, Magister en Economía aplicada de la Universidad de los EAFIT, profesora de Economía de la Universidad de Pamplona

*** Economista, Especialista en Gerencia Financiera, Especialista en Contratación Estatal y Especialista en seguridad Social: miguel.celemin@unilibre.edu.co

**** Economista, Lic Ciencias Sociales, Especialista Gestión Pública, Magister en Gobierno y Política Pública. Líder del grupo de investigación Competitividad y Sostenibilidad para el Desarrollo de la Universidad Libre. mariod.zambranom@unilibre.edu.co

\section{Resumen}

El artículo tiene como objeto realizar un análisis del contexto legal y el desarrollo conceptual de la tercerización e intermediación laboral de la figura del contrato sindical para el caso de la ESE Hospital Universitario Erasmo Meóz, a través de un estudio descriptivo de la contratación estatal e impacto en las condiciones socioeconómicas del afiliado partícipe versus el trabajador de "planta" de la empresa social del Estado.

Palabras clave: Afiliado partícipe, contrato sindical, tercerización laboral y contratación Estatal.

\section{Abstract}

The article aims to perform an analysis of the legal context and the conceptual development of outsourcing and labor intermediation of the 
figure of the union contract for the case of ESE University Hospital Erasmo Meóz, through a descriptive study of state contracting and impact in the socio-economic conditions of the participant affiliate versus the worker of the social enterprise of the State.

Keywords: Affiliate participant, union contract, labor outsourcing and State contracting

\section{Resumo}

O artigo tem como objetivo realizar um análisis do contexto legal e o desarrolho conceptual da terceirização e intermediação laboral da figura do contrato sindical nos casos da ESE Hospital universitario Erasmo Meóz, num estudo descritivo da contratação estatal e impacto nas condições socioeconômicas do afiliado participe versus o trabalhador da empresa social do Estado

Palavras chaves: afiliado participe, contrato sindical, terceirização laboral e contratação Estatal

\section{Introducción}

El Estado en aras de mejorar la eficiencia y eficacia de sus instituciones ha permitido que las entidades públicas lleven a cabo procesos de intermediación laboral sustentadas en un gran acervo reglamentario, sus principales condiciones radican entre otras, en la no existencia de vínculos directos o laborales con la administración, un carácter excepcional y periódico de las actividades desarrolladas y adicional que éstas no se puedan desarrollar por el personal directo o de "planta" contratado.

En este contexto surge el contrato sindical, como una modalidad de intermediación laboral fundamentada en los artículos 482,483 y 484 del código sustantivo del trabajo y reglado por el decreto 1429 del año 2010, cuya finalidad radica en priorizar el contrato con asociaciones sindicales en aras de promover el derecho de asociación o lo que se denominó en el gobierno del expresidente Álvaro Uribe Vélez, el nuevo "sindicalismo participativo". Ésta modalidad, aunque parte del derecho civil, se aleja del escenario laboral al eliminar el concepto de empleado subordinado y salario como medio retributivo y en su remplazo nace la definición de afiliado partícipe y compensación para los efectos de ingreso pecuniario.

Su desarrollo jurisprudencial y reglamentario no ha sido muy amplio, pero ha tenido gran aceptación, según el profesor Giraldo, entre 2009 y 2010, el número de contratos sindicales en Colombia era de 46 y 50 respectivamente, al siguiente año se firmaron 131 y en el 2012 se registraron 262, 5 veces más de los efectuados dos años atrás, reflejando un alto crecimiento y proliferación en todos los sectores de la economía. (Giraldo, La inconveniencia de los contratos sindicales de hoy, 2013)

Sus altos incrementos coinciden con la prohibición por la ley y la jurisprudencia de las cooperativas de trabajo asociado (CTA) para ejercer labores de intermediación en funciones misionales, a partir de este momento, también el contrato sindical realizó su aparición en la ESE Hospital Universitario Erasmo Meóz (HUEM), que desde el año 2012, ha venido realizando toda su contratación misional, fuera del personal de planta, con sindicatos.

El presente trabajo proporciona un análisis del contexto legal y el desarrollo conceptual de la tercerización e intermediación laboral como política de Estado, para entrar a definir el rol del contrato sindical en la función pública, especialmente del hospital universitario Erasmo Meóz. El principal objetivo es identificar los contratos sindicales en la ESE y sus principales características para determinar si es una modalidad de tercerización laboral cubierta por las vestiduras de la legalidad, profundizando las brechas socioeconómicas entre empleadas de planta y afiliadas partícipes; o si por el contrario brinda la mejor opción de empleo tal y como fue pensado por el legislador.

\section{El Estado y La Fuerza Laboral}

Históricamente el rol del Estado ha sufrido una serie de cambios como respuesta a las exigencias del entorno; la crisis de 1929 propició que la 
política Keynesiana diera origen a un Estado interventor y planificador bajo el concepto de Estado de Bienestar; su puesta en marcha, trajo consigo múltiples desequilibrios económicos debido especialmente al elevado endeudamiento interno y externo y la crisis fiscal como consecuencia del excesivo gasto público.

A partir de los años 70, la ampliación de funciones y responsabilidades del Estado con motivo del crecimiento de la estructura del aparato público, las crecientes demandas de la sociedad y el aumento excesivo de su personal, surgió la necesidad de adelgazar esa estructura organizativa y conformar un Estado mínimo: de acuerdo a lo anterior, el neoliberalismo toma fuerza como la corriente ideológica del capitalismo proponiendo un conjunto de posturas y estrategias para favorecer el posicionamiento del capital en los mercados internacionales, entre éstas se encuentra la minimización del Estado como principal promotor del desarrollo de las regiones. (Añez, 2004)

La concepción neoliberal introdujo cambios en la producción que implicaron la flexibilización del proceso de producción; cambios en la organización empresarial; intensificación e internacionalización de la producción y la comercialización; producción selectiva de acuerdo a la lógica del mercado; y separación del Estado como principal regulador de la vida social y económica, con la posibilidad de que las economías se liberen de las reglas de juego planteadas por el Estado.

La producción flexible se caracteriza por ser selectiva - responde a las exigencias individuales del consumidor - siendo la demanda la que determina que y cuanto producir, lo cual conlleva incluso a flexibilizar los contratos de trabajo mediante la reducción de los empleos fijos o regulares; el establecimiento de los empleos temporales (aprovechando la gran cantidad de mano de obra desempleada); la contratación de trabajadores según las necesidades del ciclo económico de cada empresa (determinada por la demanda del mercado); la formación de pequeños negocios familiares, domésticos, tradicionales ; y el crecimiento de las economías subterráneas e informales (Mosquera Becerra, 2016).

La fragilidad de los contratos temporales sumado a los altos niveles de desempleo, generaron incertidumbre y miedo al despedido, lo cual debilitó y fragmentó las organizaciones sindicales de trabajadores. Por lo anterior, la flexibilización laboral trajo consigo la disminución de los beneficios adquiridos por la clase trabajadora, conformando un trabajador aislado, individualizado, precarizado, no sindicalizado, con contrato de empleo temporal o parcial, y con escasas provisiones de seguridad social. (Añez, 2004)

La reorganización del sistema capitalista viene acompañada de una transformación del trabajo y de los beneficios sociales de los trabajadores al darse una ruptura de las formas tradicionales de protección social, generando la inseguridad social, la exclusión del mercado de trabajo, la pobreza extrema, hasta convertirse en una problemática social compleja.

En síntesis, el reordenamiento de la economía, transfirió la responsabilidad de diseñar y ejecutar la política de bienestar social a grupos privados, generando una mercantilización de los servicios públicos; de igual manera, se consideró la fuerza laboral como un recurso que puede ser contratado y despedido de acuerdo a los requerimientos del mercado sin ningún tipo de barrera.

En Colombia, estas tendencias de organización económica y por ende de restructuración del Estado se ponen en marcha a comienzos de los años 90 con el modelo de apertura económica, en el intento de ajustar el país a las condiciones exigidas por el proceso de internacionalización de la economía, modernización de la industria y aumento de la competitividad en el mercado mundial. Entre las políticas plasmadas en el plan 
La Revolución pacífica ${ }^{1}$, se encuentran: la modernización del Estado, la reducción de su tamaño para hacerlo eficiente, la racionalización del gasto público, la reestructuración de los organismos estatales y la privatización de las empresas públicas; por ello, en el ámbito laboral fue necesaria una reforma laboral que acompañara el modelo de apertura económica, mediante la desregulación y flexibilización de las normas del trabajo, adaptándolas a las leyes del mercado, la competitividad internacional y los nuevos patrones tecnológicos.

Sin embargo, es de resaltar que el proceso de reforma del Estado ha sido un proceso sin mayor consenso político, inducido generalmente por los poderes ejecutivos y por un grupo de tecnócratas de la mano de los organismos multilaterales bajo un formato estándar que ha llenado las expectativas en cuanto a estabilidad macroeconómica y desempeño fiscal. Por ende, la reforma del Estado del ajuste estructural logró en términos generales un Estado más pequeño y menos costoso, pero no necesariamente más eficaz y eficiente en la provisión y/o regulación de los bienes y servicios públicos. (Cuervo, 2003).

\section{Revisión Bibliográfica}

El contrato sindical como tipología es relativamente nueva en su utilización en el sector público, su auge se comenzó a evidenciar desde la prohibición por la jurisprudencia y ordenamiento legal de las cooperativas de trabajo asociado como modalidad de tercerización laboral, en consecuencia, no hay un gran acervo de estudios o literatura que trate el tema, lo que sí ha generado es un número considerable de noticas en medios

impresos y audiovisuales que reflejan la grave situación y su relación con las cooperativas de trabajo; sin embargo, sobre el tema resaltan los escritos del abogado Ricardo Barona Betancurt, y pronunciamientos de la Escuela Nacional Sindical (ENS).
El trabajo del abogado Barona, se denomina el contrato colectivo sindical: una expresión del derecho de asociación sindical o una forma de tercerización en Colombia. En el cual hace un gran recorrido legal y jurisdisprudencial del concepto, alcance y responsabilidades de las partes que intervienen en un contrato sindical. Resalta dos posiciones existentes sobre la relación laboral entre el afiliado partícipe y el sindicato; la primera de ellas está sustentada por el ministerio del trabajo y corte constitucional donde según el Literal 9 del artículo 5 del Decreto 1429 de 2010, la cartilla sobre contrato sindical del 28 de abril de 2010 del ministerio del trabajo y las sentencias de la corte constitucional T 303 y T457 del 2011. Donde argumentan y concluyen que no existe relación de subordinación y dependencia por tanto no hay relación laboral.

La segunda posición tiene de base el artículo 24 del código sustantivo del trabajo el cual establece que: "...Se presume que toda relación de trabajo personal está regida por un contrato de trabajo...". En él resalta los argumentos del doctor Afanador (p. 19), quien cita: "...El sindicato contratista se convierte en empleador de sus afiliados para la prestación de los servicios o ejecución de la obra contratada...", el profesor Figueroa (p. 19) el cual manifiesta que: "...El sindicato que actúa como contratista se compromete a ejecutar determinada obra por medio de sus afiliados. Estos, con respecto al sindicato, tienen un contrato individual de trabajo. Realizan un trabajo a favor de un tercero denominado beneficiario de la obra o prestación de servicios..." y en ésta misma línea resalta otros autores que defienden la posición de relación laboral existente entre afiliado partícipe y sindicato. (Barona, 2013)

La de Escuela Nacional Sindical (ENS) ha realizado varios pronunciamientos entorno al tema del contrato sindical, uno de ellos es: "de la cooperativa de trabajo asociado al contrato sindical: no hay ni un paso"; en la publicación se maneja la tesis de ésta modalidad como una forma de tercerización laboral, afirmando que las

\footnotetext{
1 Plan de desarrollo propuesto en el gobierno de Cesar Gaviria (1990-1994)
} 
cooperativas de trabajo asociado (CTA) han pasado hacer sindicatos con el objetivo de realizar contratación a manera de tercerización ahondando la controversia y convirtiéndose en un esguince a las normas emitidas, volviéndolas inocuas para el objetivo del empleo formal. (Giraldo, 2011)

Lo anterior, es soportado por el informe final de la investigación para la RedLAT: Situación de la subcontratación en América Latina y perspectivas para su regulación; el cual tiene 3 vértices para definir una subcontratación o tercerización que son: 1) objeto: las actividades contratadas; 2) los sujetos que intervienen (tercerizador y tercero); y 3) las relaciones jurídicas no laborales establecidas entre los dos sujetos. Entre otros la investigación afirma que:

"Hay otras formas de subcontratación, o formas tradicionales resucitadas, como es el caso en Colombia, del contrato sindical, que deslaboralizan. Este tipo de contrato, vieja figura del derecho colectivo del trabajo, quedó hibernando casi que por un siglo, representando lo que en la teoría de la evolución se llama preadaptación. En los últimos años se reactivó en Colombia en los momentos en que se le puso un tatequieto al uso desaforado de las cooperativas de trabajo asociado. Su resurgimiento pujante se está dando en particular en el sector de la confección, profundamente marcado por la subcontratación productiva y la reducción del sindicalismo a una expresión mínima. La reglamentación actual obliga a ciertos mínimos laborales, pero no garantiza unos derechos laborales y una protección social plenos". (Puig Farras, García Guzman, \& González, 2011)

Adicional, el ensayo identifica 7 riesgos principales a la hora de utilizar el contrato sindical:

1. Opera la deslaboralización. No hay un contrato laboral de por medio y como consecuencia no se tiene derecho a los beneficios consagrados en las leyes laborales, conquistados por los trabajadores históricamente y conocidos como prestaciones sociales.
2. Bajan los ingresos. Los trabajadores no reciben salarios ni prestaciones, sino una "compensación", definida por un reglamento. Y como la tercerización obedece a la lógica de la reducción de costos, en la mayoría de los casos las compensaciones no alcanzan a los mínimos laborales legales y justos y se labora en jornadas extendidas sin el pago de horas extras.

3. Riesgo de discriminación laboral. Los trabajadores objeto de la deslaboralización están en peores condiciones que los cobijados por las leyes laborales o las convenciones colectivas, lo que constituye sin duda una discriminación en materia laboral y salarial.

4. Mayor desprotección social. En el mundo, los sistemas de protección social que carecen de universalidad, como el nuestro, obedecen a unos modelos ligados a las instituciones laborales. Gozan de una mayor protección quienes tienen vinculaciones laborales permanentes y directas con los empleadores, quienes retienen y hacen los aportes a la seguridad social. La deslaboralización y la reducción de los ingresos, implica un deterioro y una mayor vulnerabilidad para la situación de los trabajadores, pues en muchas ocasiones no se surten las afiliaciones al sistema y no se hacen las cotizaciones correspondientes. De ello dan cuenta las estadísticas.

5. Riesgo de insolvencia del contratista. En la economía se presentan crisis cíclicas, que cada vez son más frecuentes; las empresas grandes con músculo económico, son las que tienen mayores posibilidades de resistencia. Pueden continuar pagando los salarios a su personal directo y permanente durante periodos de crisis, mientras que las empresas contratistas, generalmente pequeñas, de menos activos y financieramente más frágiles, como los sindicatos, en el caso de los contratos sindicales, corren el riesgo de entrar en insolvencia económica y no poder responder por las compensaciones. Y como no es salario lo que se percibe, estas compensaciones no están protegidas por las prioridades en los pagos en caso de liquidaciones, como sí lo están los emolumentos salariales. 
6. Riesgo de desempleo recurrente. Por las mismas razones relacionadas con las crisis y por los altibajos en la producción o demanda de bienes y servicios, los empresarios van a demandar mano de obra sólo en los periodos que la requieran, puesto que uno de los objetivos del outsourcing es la flexibilidad en la contratación; de tal manera que los trabajadores involucrados en la tercerización van a tener una alta rotación en los puestos de trabajo y periodos de desempleo más recurrentes, en comparación con lo que se presenta en el sistema de contrato laboral directo e indefinido.

7. Pérdida de derechos colectivos. Aunque los contratos sindicales constituyen una forma de negociación colectiva, ésta se sale del ámbito del trabajo dependiente y asalariado; por lo tanto, no aplica la negociación colectiva con el empleador de los derechos y remuneraciones individuales, no aplican sus términos, como no aplica el derecho de huelga. Los contratos sindicales están en la órbita de la contratación civil y comercial, lo mismo en el campo del trabajo asociado, a la cual corresponde una forma de asociación diferente como la propia CTA. Es que, así como las cooperativas de trabajo asociado no debieron meterse en la intermediación laboral y en el suministro de mano de obra a las empresas, de la misma manera el sindicalismo no debiera adentrarse en los espacios del trabajo cooperativo asociado; cada quien en su campo y de acuerdo con su naturaleza.

\section{Fundamentación Legal del Contrato Sindical}

El contrato colectivo sindical se encuentra regulado por el código sustantivo del trabajo y el Decreto Reglamentario 1429 de 2010, entendido como "el que celebren uno o varios sindicatos de trabajadores con uno varios patronos o sindicatos patronales para la prestación de servicios o la ejecución de una obra por medio de sus afiliados"2. Por lo tanto, el contrato colectivo sindical "es un acuerdo de voluntades, de naturaleza colectivo laboral, tiene las características de un contrato solemne, nominado

\footnotetext{
2 Artículo 482 del Código Sustantivo del Trabajo.

3 Artículo 1 del Decreto 1429 de 2010.

${ }^{4}$ Artículo 4 del Decreto 1429 de 2010.
}

y principal, cuya celebración y ejecución puede darse entre uno $o$ varios sindicatos de trabajadores con uno o varios empleadores o sindicatos de empleadores, para la prestación de servicios o la ejecución de obras con sus propios afiliados, realizado en ejercicio de la libertad sindical, con autonomía administrativa e independencia financiera por parte del sindicato o de los sindicatos y que se rige por las normas y principios del derecho colectivo del trabajo" ${ }^{3}$.

El contrato colectivo sindical será suscrito por el representante legal del sindicato de acuerdo con lo establecido en la Ley o en sus estatutos. Para todos los efectos legales, el representante legal de la organización sindical que suscriba el contrato sindical, ejercerá la representación de los afiliados que participan en el Contrato Sindical ${ }^{4}$. Es necesario que uno de los ejemplares del contrato sindical se deposite en el Ministerio de Trabajo, a más tardar quince (15) días después de su firma; la respectiva dependencia del Ministerio de la Protección Social, expedirá previa solicitud la constancia del depósito del contrato colectivo laboral ${ }^{5}$.

El sindicato de trabajadores que haya suscrito un contrato sindical, responde tanto por las obligaciones directas que surjan del mismo como por el cumplimiento de las que se estipulen para sus afiliados, salvo en los casos de simple suspensión del contrato, previstos por la ley o la convención, y tiene personería para ejercer tanto los derechos y acciones que le correspondan directamente, como las que correspondan a cada uno de sus afiliados. Para estos efectos, cada una de las partes contratantes debe constituir caución suficiente; si no se constituyere, se entiende que el patrimonio de cada contratante responde de las respectivas obligaciones ${ }^{6}$.

Además de las clausulas relativas a las condiciones específicas del objeto del contrato colectivo sindical y las circunstancias en que se desarrollará, este deberá indicar el valor total de la prestación del servicio o de la ejecución de la obra, así como la cuantía de la caución que las

\footnotetext{
${ }^{5}$ Artículo 482 del Código Sustantivo del Trabajo. Artículo 7 del Decreto 1429 de 2010. Artículo 8 del Decreto 1429 de 2010.

6 Artículo 483 del Código Sustantivo del Trabajo
} 
partes deben constituir para asegurar el cumplimiento de las obligaciones pactadas y definir de común acuerdo las auditorias que consideren necesarias para verificar el cumplimiento de las obligaciones reciprocas una vez suscrito el respectivo contrato ${ }^{7}$. El sindicato firmante de un contrato colectivo sindical, deberá establecer en su contabilidad general una subcuenta para cada uno de los contratos sindicales suscritos ${ }^{8}$.

La duración, la revisión y la extinción del contrato sindical se rigen por las normas del contrato individual de trabajo. ${ }^{9}$ Teniendo en cuenta que, en caso de disolución del sindicato de trabajadores que haya sido parte de un contrato sindical, los trabajadores continuarán prestando sus servicios en las condiciones estipuladas, mientras dure la vigencia del contrato. La caución que haya prestado el sindicato disuelto subsistirá para garantizar las obligaciones de los respectivos trabajadores ${ }^{10}$.

\section{El contrato colectivo sindical como modalidad de contratación de la ESE - HUEM}

La empresa Social del Estado, Hospital Universitario Erasmo Meóz - ESE HUEM- es una entidad con categoría especial de entidad pública descentralizada de orden departamental ${ }^{11}$. Según las atribuciones legales y especiales, su régimen de contratación se rige por el derecho privado, pero podrá discrecionalmente utilizar las clausulas excepcionales previstas en el estatuto general de la contratación de la administración pública ${ }^{12}$. El acuerdo número 008 de junio 13 de 2013 de la ESE HUEM, reglamenta el estatuto contractual estableciendo como modalidades de contratación: la contratación directa, la selección de mínima cuantía, invitación publica de menor cuantía y convocatoria pública de mayor cuantía, con el ánimo de garantizar la selección objetiva del contratista. El articulo 15 detalla las causales de la modalidad de contratación directa y entre ellas se encuentran: 1. Los contratos de

\footnotetext{
7 Artículo 3 del Decreto 1429 de 2010.

8 Artículo 6 del Decreto 1429 de 2010.

${ }^{9}$ Artículo 482 del Código Sustantivo del Trabajo.
}

adquisición de servicios de salud de mínima cuantía; 2. Contratos de prestación de servicios profesionales, técnicos, de apoyo a la gestión o para el desarrollo directo de actividades científicas, artísticas, tecnológicas $\mathrm{o}$ de capacitación que solo puedan encomendarse a ciertos artistas o expertos; 3. Contratos de operación con terceros; 4 . Convenios o contratos interadministrativos; 5. Contratos sindicales...; entre otros.

Por lo anterior, el contrato sindical se encuentra reglamentado como una causal de contratación directa para la ESE HUEM, teniendo en cuenta que de conformidad con el numeral 3 del artículo 373 del código sustantivo de trabajo, los sindicatos tienen entre sus funciones celebrar contratos sindicales, garantizar el cumplimiento por parte de sus afiliados y ejercer los derechos que de ellos nazcan.

\section{Contexto legal de la tercerización laboral en las empresas sociales de Estado}

En Colombia la apertura económica de los años 90 ' fue el resultado de la onda globalizadora que incorporó procesos y tendencias económicas, sociales y culturales; su materialización se evidencia en la Constitución y en las leyes encaminadas a eliminar las barreras del pasado y permitir la entrada y participación de nuevo actores, propios de la descentralización político administrativa del País. Lo anterior, también permitió la incursión de políticas para incentivar la inversión y crecimiento de empresas a través de mayor flexibilización en el empleo y en la economía en general.

En ese sentido se promulgó la Ley 50 de 1990, pionera en la inclusión de nuevas formas de flexibilización del empleo tales como: el contrato temporal (Art. 71 - 96); contratos a término fijo inferiores a un año (Art. 3) y contratos civiles de prestación de servicios para suprimir el pago de prestaciones sociales (Art. 2). De igual forma,

\footnotetext{
${ }^{10}$ Artículo 484 del Código Sustantivo del Trabajo.

${ }^{11}$ Ordenanza 060 de 1995, proferida por la Asamblea departamental de Norte de Santander

${ }^{12}$ Acuerdo 001. Estatuto interno de la ESE HUEM
} 
dentro de la ley 80 de 1993, actual estatuto contractual, se introdujeron los conceptos de contratación por prestación de servicios (Art.24).

La puesta en marcha de una política clara de flexibilización en los contratos, permitió que las empresas públicas, tanto de régimen de ley 80 , como aquellas que por su naturaleza poseen un régimen especial, comenzaran a formar un andamiaje de contratos caracterizados por su temporalidad e inestabilidad laboral. La figura de operación mediante terceros ha sido ampliamente utilizada por las empresas sociales del Estado (ESE), su carácter excepcional otorgado por el artículo 194 de la Ley 100 de 1993, y su Decreto Reglamentario 1876 de 1994, les permite tener su propio manual de contratación, sin embargo, no implica una completa desvinculación con el estatuto general de contratación, dado que la celebración por parte de las ESE de los contratos estatales contenidos en el artículo 32 de la Ley 80, les resulta aplicable el deber de selección objetiva; así como los demás principios que rigen la contratación estatal: transparencia, economía y responsabilidad.

Los contratos a través de terceros o de intermediación más utilizados basados en la laxitud del sistema legal han sido: la prestación de servicios, la cooperativa de trabajo asociado, las empresas temporales y el contrato sindical.

La Prestación de servicios profesionales es definida en la ley 80 en su artículo 32, como de carácter excepcional, es una modalidad frecuentemente utilizada para suplir necesidades de carácter misional y permanente en las distintas empresas Estatales, ha sido tal su mal interpretación que sobre el hecho hay más de mil acciones en las distintas instancias jurisdiccionales; la Corte Constitucional en sentencia de constitucionalidad C-614 del año 2009 pronunció lo siguiente:

"La Corte encuentra que la prohibición a la administración pública de celebrar contratos de prestación de servicios para el ejercicio de funciones de carácter permanente se ajusta a la Constitución, porque constituye una medida de protección a la relación laboral, ya que no sólo impide que se oculten verdaderas relaciones laborales, sino también que se desnaturalice la contratación estatal, pues el contrato de prestación de servicios es una modalidad de trabajo con el Estado de tipo excepcional, concebido como un instrumento para atender funciones ocasionales, que no hacen parte del giro ordinario de las labores encomendadas a la entidad, o siendo parte de ellas no pueden ejecutarse con empleados de planta 0 se requieran conocimientos especializados. De igual manera, despliega los principios constitucionales de la función pública en las relaciones contractuales con el Estado, en tanto reitera que el ejercicio de funciones permanentes en la administración pública debe realizarse con el personal de planta, que corresponde a las personas que ingresaron a la administración mediante el concurso de méritos."

Las cooperativas de trabajo asociado son aquellas que vinculan el trabajo personal de sus asociados para la producción de bienes, ejecución de obras o la prestación de servicios (Art. 70 ley 79/88), la corte constitucional mediante dos sentencias (Sentencia C - 211, 2000) y (Sentencia C- 645, 2011), ha reafirmado la importancia de la actividad:

"La jurisprudencia constitucional ha destacado la importancia de las Cooperativas de Trabajo Asociado y ha reconocido que las mismas gozan de especial protección constitucional, como modalidad de trabajo y como expresión del sector solidario. Ha dicho la Corte que, los elementos esenciales del contrato de constitución de una cooperativa de trabajo asociado son los siguientes: (i) Pluralidad de personas, (ii) aporte principalmente en trabajo, (iii) objeto de interés social y sin ánimo de lucro, y (iv) calidad simultánea de aportante y gestor. En la Sentencia C- 211 de 2000, la Corte identificó como características relevantes de las cooperativas de trabajo asociado las siguientes: (i) asociación voluntaria y libre, (ii) igualdad de los cooperados, (iii) ausencia de ánimo de lucro, (iv) organización democrática, (v) trabajo de los asociados como base fundamental, (vi) desarrollo de actividades económico sociales, (vii) 
solidaridad en la compensación o retribución, y (viii) autonomía empresarial. También ha señalado la Corporación que, de acuerdo con el artículo 59 de la Ley 79 de 1988, en las cooperativas de trabajo asociado, el régimen de trabajo, de previsión, seguridad social y compensación, será establecido en los estatutos y reglamentos, como quiera que tales materias tienen origen en el acuerdo cooperativo y escapan del ámbito de regulación de la legislación laboral. Esta figura cuenta con fundamento en el principio de solidaridad y tiene manifestaciones tanto desde la perspectiva del derecho de asociación como desde el derecho al trabajo"

No obstante a lo mencionado, las cooperativas desde su regulación en el art. 17 del decreto 4588 del 2006, prohíbe de forma taxativa contratar como intermediario o empresas de servicios temporales; de igual forma la ley 1233 de 2008 en su artículo 7, numeral primero estableció que "las Cooperativas y Precooperativas de Trabajo Asociado no podrán actuar como empresas de intermediación laboral, ni disponer del trabajo de los asociados para suministrar mano de obra temporal a terceros o remitirlos como trabajadores en misión. En ningún caso, el contratante podrá intervenir directa o indirectamente en las decisiones internas de la cooperativa y en especial en la selección del trabajador asociado".

La corte constitucional hizo referencia a estos casos en su sentencia C-614/2009 de la siguiente manera:

"De hecho, esta Corporación reitera de manera enfática la inconstitucionalidad de todos los procesos de deslaboralización de las relaciones de trabajo que, a pesar de que utilizan formas asociativas legalmente válidas, tienen como finalidad última modificar la naturaleza de la relación contractual y falsear la verdadera relación de trabajo. Por ejemplo, en muchas ocasiones, las cooperativas de trabajo asociados, que fueron creadas por la Ley 79 de 1988, modificadas por la Ley 1233 de 2008 y reglamentadas por el Decreto 3553 de 2008, para facilitar el desarrollo asociativo y el cooperativismo, se han utilizado como instrumentos para desconocer la realidad del vínculo laboral, a pesar de que expresamente el artículo $7^{\circ}$ de la Ley 1233 de 2008, prohíbe su intermediación laboral.

Así, la eficacia normativa de la Constitución que protege de manera especial la relación laboral y la aplicación del principio de primacía de la realidad sobre la forma, impone a los particulares y a todas las autoridades públicas, de una parte, el deber de acatar las prohibiciones legales dirigidas a impedir que los contratos estatales de prestación de servicios (norma acusada) y las cooperativas y precooperativas de trabajo asociado sean utilizadas como formas de intermediación laboral (artículo $7^{\circ}$ de la Ley 1233 de 2008) y, de otra, la responsabilidad social de evitar la burla de la relación laboral".

Por último, la ley 1233 del 2008 en su artículo 63, prohíbe la contratación de personal para el desarrollo de las actividades misionales permanentes a través de cooperativas de servicio de trabajo asociado que hagan intermediación laboral o bajo ninguna otra modalidad de vinculación que afecte los derechos constitucionales, legales y prestacionales consagrados en las normas laborales vigentes, este artículo es reglamentado por el Decreto 2025 del 2011, el cual se dictan sanciones a quienes ejerzan la actividad prohibida.

Otra de las formas que llaman la atención en contratación de personal en las ESE, es el denominado "Contrato Sindical", aún muy reciente para catalogarlo bajo las premisas de las entidades jurisdiccionales como tercerización laboral. De nuevo este tipo de contrato, desdibuja la relación laboral de subordinación entre empleador y empleado, llamándose ahora "afiliado participe" aquel que dentro de su afiliación y cumpliendo con un reglamento del contrato sindical, ejecuta las acciones encomendadas en este caso por el colectivo en concordancia con la entidad contratante.

Sobre el tema la corte constitucional se ha pronunciado en la sentencia T-457/2011: 
"... Ahora bien, en el contrato sindical intervienen el empresario-empleador y la organización sindical. Las personas que se afilian al sindicato para prestar sus servicios o realizar las obras encomendadas a través de dicho contrato, se denominan afiliados partícipes. Cabría entonces una pregunta: ¿Los afiliados partícipes que están bajo la modalidad del contrato sindical tienen un contrato de trabajo con la organización sindical? La respuesta es no, porque no existe el elemento esencial de la subordinación propio del contrato de trabajo. El afiliado partícipe durante la ejecución del contrato sindical compone el sindicato y se encuentra en un plano de igualdad con éste frente a la distribución de los ingresos provenientes del contrato, al punto que recibe compensaciones y son sujetos de ciertas deducciones, las cuales para todos sus efectos se asimilan al concepto de salario, de acuerdo con lo definido en la asamblea de afiliados, en el reglamento y en el contrato sindical. Quiero ello decir que entre el sindicato y los afiliados partícipes no existe como tal una relación empleador-trabajador, pues si se viera desde la óptica contraria comprometería gravemente el derecho de sindicalización en Colombia (artículo 39 Superior), toda vez que quienes se agrupan para defender sus intereses laborales en contra del empleador, resultaría a su vez detentando la figura de patrono a través de la persona jurídica que constituye el sindicato, situación que resulta ser un contrasentido..." (Sentencia T - 457, 2011)

Adicional el ministerio del trabajo en el concepto 144386 mencionó que "teniendo en cuenta que en el contrato sindical no hay una relación subordinada que permita establecer una vinculación entre trabajador y empleador, no existe obligación de pagar aportes parafiscales" y respecto a los aportes a cajas de compensación podrán ser voluntarios.

Aun no hay un fallo de prohibición a esta tipología de contratación en la administración pública, por lo cual, actualmente esta modalidad se encuentra en crecimiento y expansión en todo el territorio, generando cada día más contratos sindicales y afiliados participes, en muchas formas, se asemejan a la precaria inestabilidad e incertidumbre laboral de quienes desempeñan labores misionales, permanentes, de apoyo o cualquiera que sea su denominación sin ser empleados.

\section{Contratación de la ESE HUEM}

El contrato sindical en La ESE HUEM para cumplir a cabalidad con sus labores tanto administrativas como misionales hace uso especialmente de dos tipos de personal, según su contratación: personal de planta y personal por agremiaciones. Este último representa el mayor porcentaje dentro del total de personal de la entidad (gráfico 1); razón por la cual hace un uso intensivo de la modalidad de contratos sindicales quienes son los mayores proveedores de personal, el $67 \%$ de los contratos con agremiaciones son sindicales, lo cual representa un cerca de 8 mil millones de pesos contratados por esta modalidad en lo corrido del año 2014.

Gráfico 1. Personal de planta y agremiación

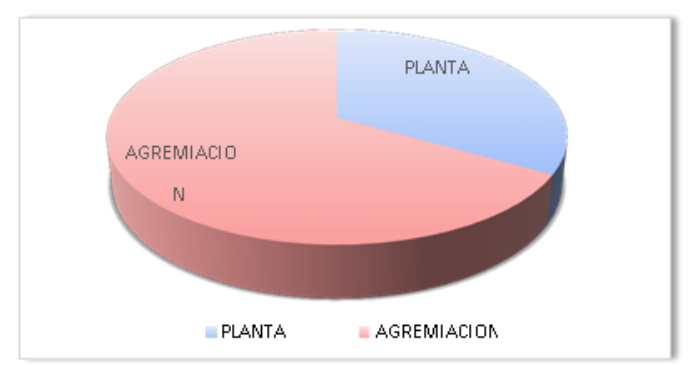

FUENTE: Departamento de Talento Humano de la ESE HUEM

Por lo anterior, el contrato sindical es una modalidad significativa dentro de los procesos de contratación de la ESE HUEM, especialmente para subsanar los servicios asistenciales de la Entidad, los cuales representan el $76 \%$ de los contratos sindicales, el $24 \%$ restante se realizan para labores administrativas; el servicio que mayor utilización hace del contrato sindical es el de auxiliar de enfermería con cerca del 31\% del total de contratos sindicales.

Según la información registrada en el SECOP, el 14\% de la contratación llevada a cabo en el 2014 (hasta marzo) corresponde a contratos sindicales para labores asistenciales misionales, lo cual 
equivale al $14 \%$ del presupuesto ejecutado en servicios de personal.

Entre los años 2011 y 2013 la participación de los contratos de servicios misionales en el presupuesto ejecutado disminuyó, como se observa en el gráfico 2; debido en gran parte a la pérdida de dinamismo de la entidad (disminución en la cantidad de servicios prestados), razón por la cual su presupuesto también se ha visto afectado, pasó de ejecutarse $\$ 96.920 .463 .966$ en 2011 a $\$ 88.528 .894 .255$ en 2013.

Gráfico 2. Participación de servicios misionales en el presupuesto ejecutado



FUENTE: Colombia Compra Eficiente - SECOP

El gráfico 3 ilustra los gastos en personal operativo ejecutados por la entidad en donde se observa que entre los años 2011 y 2014, la ESE HUEM destinó la mayor parte de este rubro para contratos indirectos, aun por encima de los gastos de nómina.

Gráfico 3. Distribución del presupuesto para personal operativo.

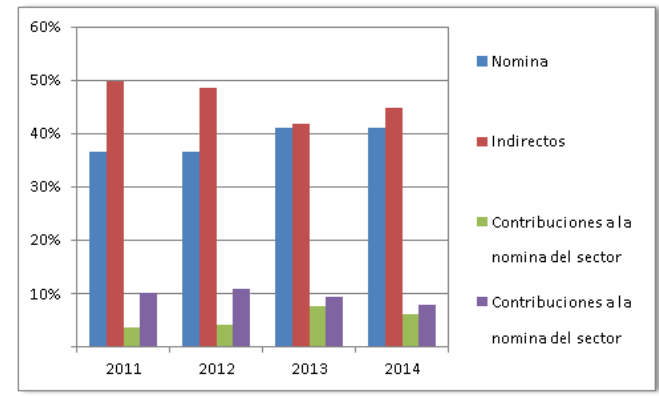

FUENTE: Departamento de Talento Humano de la ESE HUEM
Por otra parte, la participación de los contratos sindicales misionales dentro del total de los procesos de contratación llevados a cabo por la entidad ha decrecido, comportamiento motivado especialmente por la disminución del presupuesto para personal operativo, el cual pasó de 38.869.690.945 en 2011 a 32.996.254.863 en 2013, este comportamiento generó una gran cantidad de despidos en donde los más afectados fueron aquellos con mayor inestabilidad laboral, es decir los empleados por contrato sindical.

Gráfico 4. Participación Servicios Asistenciales Misionales en el total de los Contratos



FUENTE: Colombia Compra Eficiente - SECOP

En cuanto al ritmo de contratación llevado a por la entidad para los procesos de contratación sindical para servicios asistenciales existen concentración entre los meses de enero y febrero, dado que es una necesidad recurrente de la entidad, pero dichos contratos son firmados a un término de diez u once meses, por lo cual deben ser renovados anualmente.

\section{Brecha socioeconómica entre el personal por contrato de "planta" y el contrato sindical.}

La modalidad de contrato sindical en la ESE HUEM, es una figura de tercerización laboral que permite el cumplimiento de labores misionales vitales para la prestación del servicio, actualmente el hospital requiere $68.704 \mathrm{~h} / \mathrm{m}$ (horas mensuales) solo en demanda de servicio de auxiliares de enfermería, de las cuales solo cuenta con $30.102 \mathrm{~h} / \mathrm{m}$ procedentes de 158 
auxiliares de enfermería de planta ${ }^{13}$, argumento que justifican la contratación por un valor \$3.443.315.250 Mcte, en servicios de misionales de solo auxiliares de enfermería a un término de 10 meses de ejecución. Por lo anterior, el hospital cumple el artículo segundo de la Constitución Política de Colombia, garantizando el cumplimiento de los fines esenciales del Estado en esa materia; sin embargo, el fin no justifica los medios en un Estado social de Derecho, donde el accionar del servidor público se rige bajo los principios de la transparencia, moralidad, igualdad, economía, eficacia, imparcialidad y demás establecidos en la constitución y la ley.

Teniendo en cuenta lo anterior y como principio rector la selección objetiva al contratar el personal; que por ordenamiento legal $y$ constitucional debe ser de forma directa en aquellas funciones de carácter misional, se realizó un análisis del contrato No 005 del 2014, entre el hospital y el sindicato Nortesantandereano de trabajadores de la industria de la salud SINTRASALUD-. En la presente anualidad, el hospital ha contratado más de 7 mil millones de pesos en servicios de orden misional, sin embargo, se tomó para su análisis solo el contrato con SINTRASALUD, dado que es el de mayor cuantía y el que contiene más personal o afiliados participes laborando en el HUEM.

El contrato sindical No. 005/14, se adjudicó de forma directa por un monto $\$ 3.443 .315 .250$, en el cual se pacta la prestación del servicio de 200 auxiliares de enfermería (afiliados partícipes) para desempeñar labores propias del oficio en:

$\begin{array}{ll}\text { - } & \text { Urgencias } \\ \text { - } & \text { Consulta Externa de Adultos y Niños } \\ \text { - } & \text { Quirófanos } \\ \text { - } \quad \text { Sala de parto } \\ \text { - } \quad \text { Sala de recuperación }\end{array}$

${ }^{13}$ Contrato colectivo sindical 005 del 2014, proceso ss14-016, página 2

${ }^{14}$ El valor fue hallado con el informe del certificado de ingresos y retenciones del año gravable 2013 de auxiliares de

\section{- $\quad$ Central de Esterilización \\ - $\quad$ Epidemiologia \\ - $\quad$ Otros relacionados con la ESE HUEM}

Su naturaleza por ser contrato sindical se encuentra establecida en la cláusula décimo segunda, donde estable "el contratista desarrollará el objeto del contrato bajo su propia responsabilidad y plena autonomía técnica y administrativa, conforme las condiciones pactadas. En consecuencia, no existirá ninguna clase de vínculo laboral entre las partes ni las personas que el contratista emplee para la ejecución del presente contrato..." (Contrato No. 005/14) Lo anterior es paradójico proviniendo de un sindicato de trabajadores, donde su composición etimológica proviene del


justicia y como una de sus definiciones la defensa y promoción del interés laboral frente al empleador, por tanto su relación teoría carece de sustento en la praxis que se lleva a cabo en dicha modalidad de contratación.

El costo promedio mensual de una auxiliar de enfermería establecido en la cláusula sexta, es de $\$ 1.721 .658$, el cual corresponde a valor hora corriente de $\$ 8277$. El pagó es sujeto a las apropiaciones presupuestales y a la radicación de la cuenta de cobro por el contratista; escenario que genera incertidumbre al "afiliado participe" dado la crisis e inestabilidad económica que afronta el hospital, situación que ha hecho del pago de la "compensación" un mínimo vital recibido cada 2 o 3 meses, problemática que de nuevo pone entre dicho la condición de sindicato como ente custodio del interés de sus afiliados.

El costo promedio mensual de una auxiliar de enfermería de "planta" es \$1.895.48314, su diferencia promedio es de $\$ 173.825$ teniendo en cuenta que ésta realidad viene desde hace más 15 años, es irrisoria en cuanto al abandono de políticas que conlleven a integrar a los

enfermería en promedio del servicio con contrato directo (planta). 
trabajadores, llamados hace unos años prestadores de servicios, asociados cooperativos y hoy denominados afiliados partícipes de una empresa llamada SINDICATO.

Actualmente la participación en personal de planta versus afiliados partícipes, es del $67 \%$ para los agremiados, superando al personal de planta, ahora bien, esta condición no es nueva, en entrevistas realizadas algunas asociadas se evidenció el recorrido por diferentes modalidades desde OPS, cooperativas de trabajo asociados hasta la continua movilidad entre distintos sindicatos de trabajo. Algunas de ellas llevan más de 5 años en ésta evolución con contratos no superiores a 9 meses y algunos hasta de 3 meses, acentuando la incertidumbre e inestabilidad laboral, muchas de los "afiliados participes" descobijados del estatus de trabajador, son mujeres cabezas de familia, con carga económica en sus hombros y un generalizado descontento en su condiciones laborales, el valor de la compensación básica es de 820.000 mil pesos, un $50 \%$ inferior al salario del personal que realiza las mismas actividades pero con el estatus de empleado directo del hospital, el valor de la hora festiva para el agremiado es de 2.562 pesos, un 60\% inferior al acordado en el contrato 005/14 del valor hora y adicional, la compensación en el común regular se cancela cada 2 meses vencidos, en el material recolectado se evidenció que los valores de enero y febrero se cancelaron en marzo y la siguiente compensación se realizó en mayo por el mes de marzo, incrementando la brecha entre dos trabajadores que realizan una misma actividad.

\section{Conclusiones}

Desde la apertura el intento de ajustar el país a las condiciones exigidas por el proceso de internacionalización de la economía, modernización de la industria y aumento de la competitividad en el mercado mundial, ha impulsado una serie de reformas y métodos "innovadores" que han desregularizado y flexibilizado las normas del mercado del trabajo.

El contrato sindical desdibuja la relación laboral de subordinación entre empleador y empleado, llamándose ahora el históricamente trabajador "afiliado participe", aquel que dentro de su afiliación y cumpliendo con un reglamento del contrato sindical, ejecuta las acciones encomendadas en este caso por el colectivo en concordancia con la entidad contratante, situación que dista en la realidad dado que esta figura se utiliza para reemplazar las denominadas cooperativas de trabajo asociado deteriorando las condiciones socioeconómicas del empleado.

La brecha de desigualdad en el "salario" o la denominada compensación entre un afiliado partícipe que realiza las mismas actividades que un trabajador de "planta" del Hospital Erasmo Meóz es en promedio inferior un 50\%, situación que a toda luz afecta la dignidad del trabador que está desprotegido por la misma figura que históricamente ha defendido los intereses de los trabajadores, El sindicato.

\section{Referencias}

Acuerdo 008. (13 de junio de 2013). Asamblea Departamental. Estatuto contractual de la ESE Hospital Erasmo Meóz. Cúcuta, Colombia.

Añez, C. (2004). El Estado del Bienestar social y el neoliberalismo ante los derecho laborales. Revista de ciencias sociales, 19(1), 70-82. Obtenido de http://www.redalyc.org/pdf/280/280101 06.pdf

Barona, R. (2013). El contrato colectivo sindical: una expresión del derecho de asociación o una forma de tercerización en Colombia. (U. d. Montevideo, Ed.) Revista de derecho(24), 11-21. Obtenido de http://revistaderecho.um.edu.uy/wpcontent/uploads/2014/02/BaronaBetancourt-El-contrato-colectivosindical-una-expresion-del-derecho-deasociacion-sindical-o-una-forma-detercerizacion-en-Colombia.pdf 
Cuervo, J. I. (2003). La reforma del estado y el ajuste estructural en América Latina. El caso de Colombia. (U. d. Externado, Ed.) Revista Ópera, I//(3), 67-110. Obtenido de http://www.redalyc.org/pdf/675/675303 05.pdf

Decreto 1429. (28 de abril de 2010). Presidente de la República de Colombia. Por el cual se deroga el Decreto 657 de 03 de marzo del 2006,y se reglamentan los artículos 482, 483 Y 484 del Código Sustantivo de Trabajo y se dictan otras disposiciones. Bogotá D.C, Colombia: Diario Oficial 47694 de abril 28 de 2010. Obtenido de http://www.alcaldiabogota.gov.co/sisjur/ normas/Norma1.jsp?i=39430

Decreto 1876. (5 de agosto de 1994). El Presidente de la República de Colombia. Por el cual se reglamentan los artículos 96, 97 y 98 del Decreto Ley 1298 de 1994 en lo relacionado con las Empresas Sociales del Estado. Bogotá D.C, Colombia: Diario Oficial No. 41.480 de fecha 5 de agosto de 1994. Obtenido de http://www.alcaldiabogota.gov.co/sisjur/ normas/Norma1.jsp?i=3356

Decreto 2025. (8 de junio de 2011). El Presidente de la República de Colombia. Por el cual se reglamenta parcialmente la Ley 1233 de 2008 y el artículo 63 de la Ley 1429 de 2010. Bogotá D.C, Colombía: Diario Oficial 48094 de Junio 8 de 2011. Obtenido de http://www.alcaldiabogota.gov.co/sisjur/ normas/Norma1.jsp?i=43032

Decreto 4588. (27 de Diciembre de 2006). El presidente de la república de Colombia. Por el cual se reglamenta la organización y funcionamiento de las Cooperativas y Precooperativas de
Trabajo Asociado. Bogotá D.D, Colombia: Diario Oficial 46494 de diciembre 27 de 2006.

Giraldo, H. (2011). De la cooperativa de trabajo asociado al contrato sindical: no hay ni un paso. Revista Cultura y Trabajo, 14-20. Obtenido de http://www.ens.org.co/wpcontent/uploads/2017/02/CT_84.pdf

Giraldo, H. (2013). La inconveniencia de los contratos sindicales de hoy. Revista Cultura y Trabajo(87), 85-96. Obtenido de http://www.ens.org.co/wpcontent/uploads/2013/01/CT-8788_opt.pdf

Ley 100. (23 de diciembre de 1993). Congreso de la República de Colombia. Por la cual se crea el sistema de seguridad social integral y se dictan otras disposiciones. Bogotá D.C, Colombia: Diario Oficial No. 41.148 de 23 de diciembre de 1993. Obtenido de http://www.secretariasenado.gov.co/sen ado/basedoc/ley_0100_1993.html

Ley 1233. (22 de Julio de 2008). El Congreso de Colombia. Por medio de la cual se precisan los elementos estructurales de las contribuciones a la seguridad social, se crean las contribuciones especiales a cargo de las Cooperativas y Precooperativas de Trabajo Asociado... Bogotá D.C, Colombia: Diario Oficial 47058 de julio 22 de 2008. Obtenido de http://www.secretariasenado.gov.co/sen ado/basedoc/ley_1233_2008.html

Ley 50. (28 de diciembre de 1990).

Congreso de la República. Por la cual se introducen reformas al Código Sustantivo del Trabajo y se dictan otras disposiciones. Bogotá D.C, Colombia. 
Ley 79 de 1988. (10 de enero de 1989). Congreso de la República. Por la cual se actualiza la Legislación Cooperativa. Bogotá D.C, Colombia: Diario Oficial 38648 de enero 10 de 1989.

Ley 80 . (28 de octubre de 1993). Congreso de la república de Colombia. Estatuto General de Contratación de la Administración Pública. Bogotá D.C, Colombia: Diario Oficial No. 41.094 de 28 de octubre de 1993. Obtenido de http://www.secretariasenado.gov.co/sen ado/basedoc/ley_0080_1993.html

Mosquera Becerra, J. (2016). El sistema general de seguridad social en salud de Colombia: El caso de la ciudad de Cali. Universidad del Valle. Cali: Observatorio de recursos humanos en salud Universidad del Valle, Ministerio de Protección Social y Organización panamericana de la salud. Obtenido de https://www.minsalud.gov.co/sites/rid/Li sts/BibliotecaDigital/RIDE/INEC/UNIV/rel aciones-laborales-sector-salud.pdf

Puig Farras, J., García Guzman, N., \& González, J. D. (2011). Situación de la subcontratación en América y perspectivas para su regulación (primera ed.). Medellín: Escuela Nacional Sindical. Obtenido de http://209.177.156.169/libreria_cm/archi vos/pdf_522.pdf

Sentencia C - 211. (1 de 03 de 2000). Corte Constitucional, Sala Plena. M.P: Dr. Carlos Gaviria. Bogotá: Referencia: expediente D-2539. Obtenido de http://www.corteconstitucional.gov.co/re latoria/2000/C-211-00.htm

Sentencia C- 645. (31 de 08 de 2011). Corte Constitucional, Sala Plena. M.P: GABRIEL EDUARDO MENDOZA MARTELO.
Bogotá, Colombia: Referencia: expediente D-8428. Obtenido de http://www.corteconstitucional.gov.co/re latoria/2011/C-645-11.htm

Sentencia T - 457. (27 de Mayo de 2011). Corte Constitucional, Sala Novena de Revisión. M.P: LUIS ERNESTO VARGAS SILVA. Bogotá D.C, Colombia: Referencia: expediente T-2716705. Obtenido de http://www.corteconstitucional.gov.co/re latoria/2011/T-457-11.htm

Setencia C - 614. (2 de septiembre de 2009). Corte Constitucional, sala plena. M.P: Dr. JORGE IGNACIO PRETELT CHALJUB. Bogotá D.C, Colombia: Referencia: expediente D-7615. Obtenido de http://www.corteconstitucional.gov.co/ relatoria/2009/c-614-09.htm 